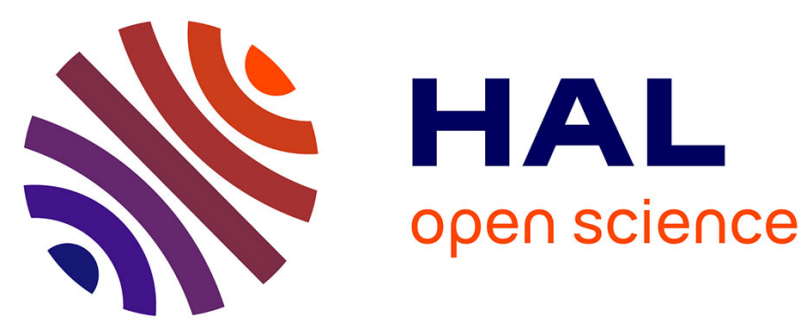

\title{
Chronicle of a scenario graph: from expected to observed learning path
}

\author{
Mathieu Vermeulen, Nadine Mandran, Jean-Marc Labat
}

\section{To cite this version:}

Mathieu Vermeulen, Nadine Mandran, Jean-Marc Labat. Chronicle of a scenario graph: from expected to observed learning path. 11th European Conference on Technology Enhanced Learning (EC-TEL 2016), Sep 2016, Lyon, France. pp.321-330, 10.1007/978-3-319-45153-4_24 . hal-01322571

\section{HAL Id: hal-01322571 \\ https://hal.science/hal-01322571}

Submitted on 4 Oct 2016

HAL is a multi-disciplinary open access archive for the deposit and dissemination of scientific research documents, whether they are published or not. The documents may come from teaching and research institutions in France or abroad, or from public or private research centers.
L'archive ouverte pluridisciplinaire HAL, est destinée au dépôt et à la diffusion de documents scientifiques de niveau recherche, publiés ou non, émanant des établissements d'enseignement et de recherche français ou étrangers, des laboratoires publics ou privés.

$$
\text { Copyright }
$$




\title{
Chronicle of a scenario graph: from expected to observed learning path
}

\author{
Mathieu Vermeulen ${ }^{1}$, Nadine Mandran ${ }^{2}$, and Jean-Marc Labat ${ }^{1}$ \\ ${ }^{1}$ LIP6, UPMC, Sorbonne Universités \\ ${ }^{1}$ \{mathieu.vermeulen, jean-marc. labat\}@lip6.fr \\ ${ }^{2}$ LIG, Université Grenoble ALPES \\ ${ }^{2}$ nadine.mandran@imag. $\mathrm{fr}$
}

\begin{abstract}
This paper proposes an analysis of student paths into the scenario graph for a learning game that uses a formal model of serious games understandable and usable by teachers. Screenwriting, implemented with a mental map, includes an expected path: the one that includes the most interesting nodes of the scenario graph from the point of view of the teacher, and achieves the training objectives. Through the analysis of the paths taken by the students, we will show the advantages and the benefits of this screenwriting. For that we indicate the different paths, the exit points (nodes presenting the case of abandonment of the student) and the various categories of paths (with achievement or nonachievement of training objectives). Finally, we propose solutions (tools and methods) to improve the reengineering process and the design of the scenario by the teachers.
\end{abstract}

Keywords: Learning games, Screenwriting, Design, Teachers, Reengineering

\section{Introduction}

The "serious games" term (or learning game for our case) has several definitions depending on the context and authors such as Abt [1] or Michael and Chen [16]. Alvarez and Djaouti provide a definition clarifying the ambiguity of the concept: a serious game is a computer application for which the original intention is to combine with consistency, serious aspects, in this case learning, with playful elements taken from the video game [2]. Many achievements have shown their interest in the transfer of skills and knowledge by developing the attractiveness and promoting the motivation to learners. Nonetheless, that interest is tempered by the lack of tools and methodologies for the design and production [11]. Meanwhile, the world of higher education is impacted, but with less enthusiasm. Teachers in higher education, even those that are convinced of the potential of digital education, have difficulties to create and to adapt learning games to their pedagogy [5]. Particularly, their implication in the design of the scenario is a crucial point of the learning game development [13]. In addition, we know that reengineering of learning games and of their scenario is a criterion of adoption 
by the teachers [14].

The research pointed out that the reengineering process needs feedbacks on the usage of the students of the TEL Systems [3]. In our case, these feedbacks are logs files and data that describe the path of the student through the scenario graph. We interpret these data in order to compare the teacher's expected path with the student's path. We could use the term of "expected scenario" and "observed scenario" [8].

In this paper, through the use of a learning game presented in the next section, we analyse the data of 155 learners (we use this term rather than students in this paper due to the profile type of this population as describe in section 3). They have used this game from 2016 March, 7th to 2016 March, 18th. This analysis would allow to make a reengineering process of these learning game with the teachers. With this, we search to make the game more efficient and to allow learners to acquire competencies, and for that to pass through the important nodes of the scenario graph. Another goal is to affine our methodology for designing learning games.

\section{Development of the Learning Game}

We have developed a learning game called "Les ECSPER" which allows to evaluate knowledge in Statistic and to acquire competencies about methodology in statistic problems in enterprise (Fig. 1).

The learner makes hypotheses and choices while playing as a young engineer

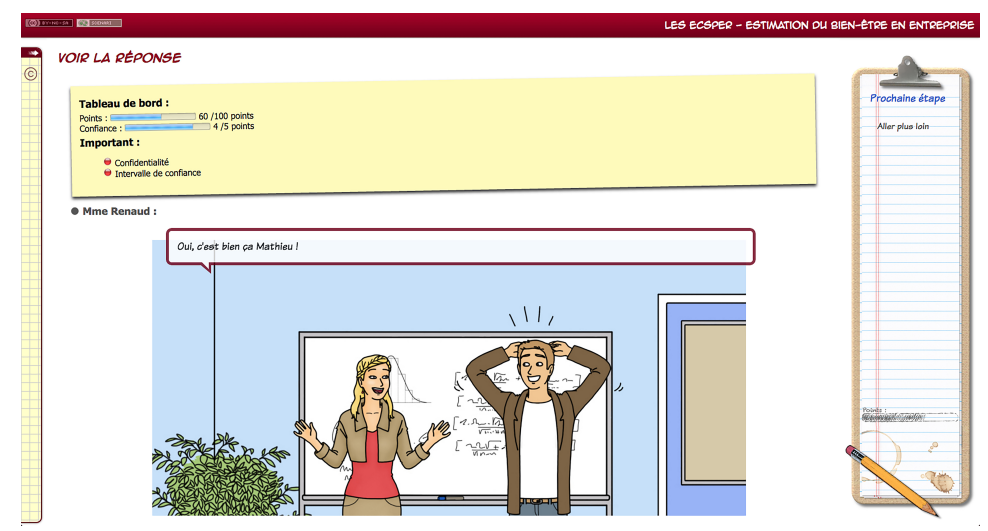

Fig. 1. A screen of the learning game Les ECSPER

employed as statistician in a big company. His/her mission is to estimate the wellness of the employees. We have two manners to evaluate the learner: a score for progression (points) and lives (3 lives in the beginning).

As we have already indicated, numerous works pointed out the difficulties for 
teachers to design and to create a learning game [10][12][4]. Particularly, if we focus on screenwriting and scenario, researches have been realized and some generic models and tools deal with this aspect of the design process. Marne et al. [12][14] have extracted from the study of different authoring tools three fundamental features about the scenario of learning games :

- The scenario is divided into components (and partially independent from each other),

- These components (e.g. levels or stages) are organized and connected by the hierarchical structure of their goals.

- The scenario components can dynamically adapt to the choices and performances of the learner (or "player").

Furthermore, we have designed the game following a conceptual framework named "the six facets" [15]. The facet "Problems and Progression" concerns "which problems to give the players to solve and in which order". This facet was a real challenge for the authors because it implies both the teachers and the game experts who must communicate with each other.

The scenario of Les ECSPER follows these features. Thus, it was inspired by gamebooks and divided into components; each of them is a case study with an educational goal. The teachers designed the scenario step by step with an iterative process and implemented it with a mental map and the tool XMind (Fig. 2). This tool is easy to use and can be used by the teachers who are not computer specialist, and of course by the game experts.

We obtained a scenario graph that contains the expected path e.g. the one

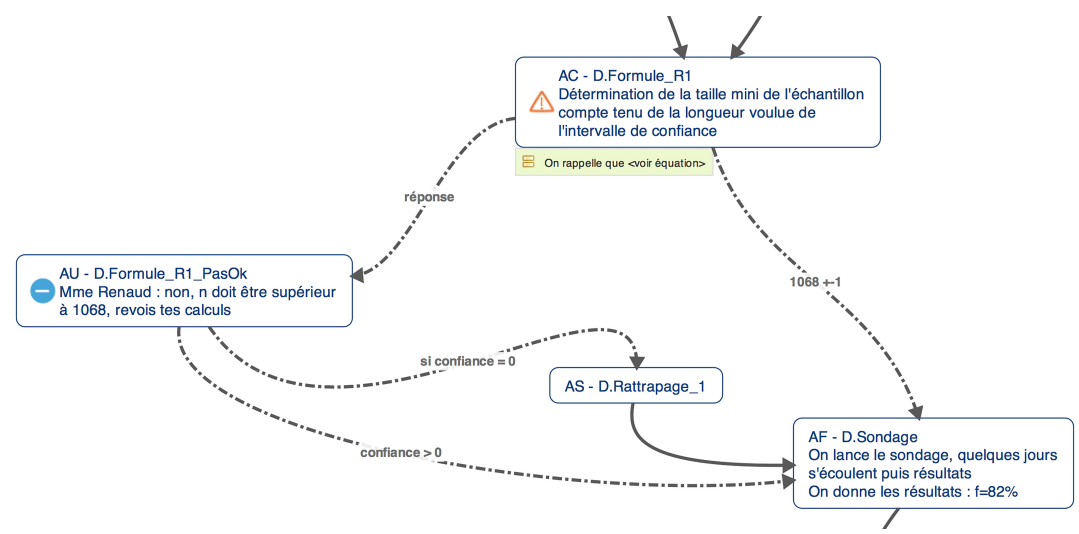

Fig. 2. An extract of the mind map describing the scenario graph

which includes the most interesting nodes of the scenario graph from the point of view of the teachers, and achieves the training objectives. It is composed by different types of nodes, which were defined by their objective. We count a very large number of paths, more than 16000, and 65 nodes; each of them is a case 
study, an expositive step or an end step. Some nodes have a large degree that represents numerous hypotheses.

\section{Context and Background of the Learners}

The learning game Les ECSPER have been designed to be an activity of a MOOC (Massive Open Online Course) named "Statistique pour l'ingénieur" (in French and means statistic for engineers). This MOOC is deployed on FUN (e.g. France Université Numérique), based on the LMS Open edX (Learning Management System). The teachers want to multiply activities and to include learning games in this MOOC [7]. The game is deployed on the LMS Moodle. We have implemented an API on this LMS to record different data such as steps (nodes) ordered chronologically, time spent by step and scores. With that data, we can induce the paths taken by each learners. The learners accede anonymously to Les ECSPER through the IMS LTI protocol [6] with a unique number (id). If another session is made for an id, it count as a second (or third) try associated with the same id. Thus, each record is associated to one unique user and available in Moodle in a .csv file. In sum, FUN provides information about the learners profile and Moodle provides data about the use of the game. However, we can't link these data because the policy of FUN imposes anonymity.

The LMS FUN provides the profile of the 6958 learners registered (as noticed at 2016 March, 24). We can state that a large part of them have at least a master's or professional degree $(64 \%)$; they have or search a job $(68 \%)$ and have more than 25 years old $(74 \%)$.

\section{Analysis}

As we have already indicated, the data were recorded from 2016 March, 7 to 2016 March, 18. Learners were on the third week of the MOOC and the prerequisites were viewed since 2 weeks through different classical activities (lectures, videos, documents and quiz). These data show a lot of different paths: 139 paths for 155 unique learners. We have categorized these paths and compared them to the expected path design by the teachers. The first step of our analyse is to count, for each learner, the number of viewed nodes (Fig. 3). We can notice that the learners who finished the game have viewed more than 38 nodes. This reflects the effort that was needed to achieve the game. We have choosen to describe 4 categories in this paper:

1. The dropouts, learners who have viewed 8 nodes or less.

2. The learners who have achieved the game with success.

3. The learners who have achieved the game with a "game over".

4. The abandonments, learners who haven't achieved the game (they have enventually done another game session) and made more than $35 \%$ of the game.

This choice allows us to show the interest of this analysis for the teachers in order to make a reengineering of the learning game. For that we pointed out a major mistake of the learners made late in the game. 


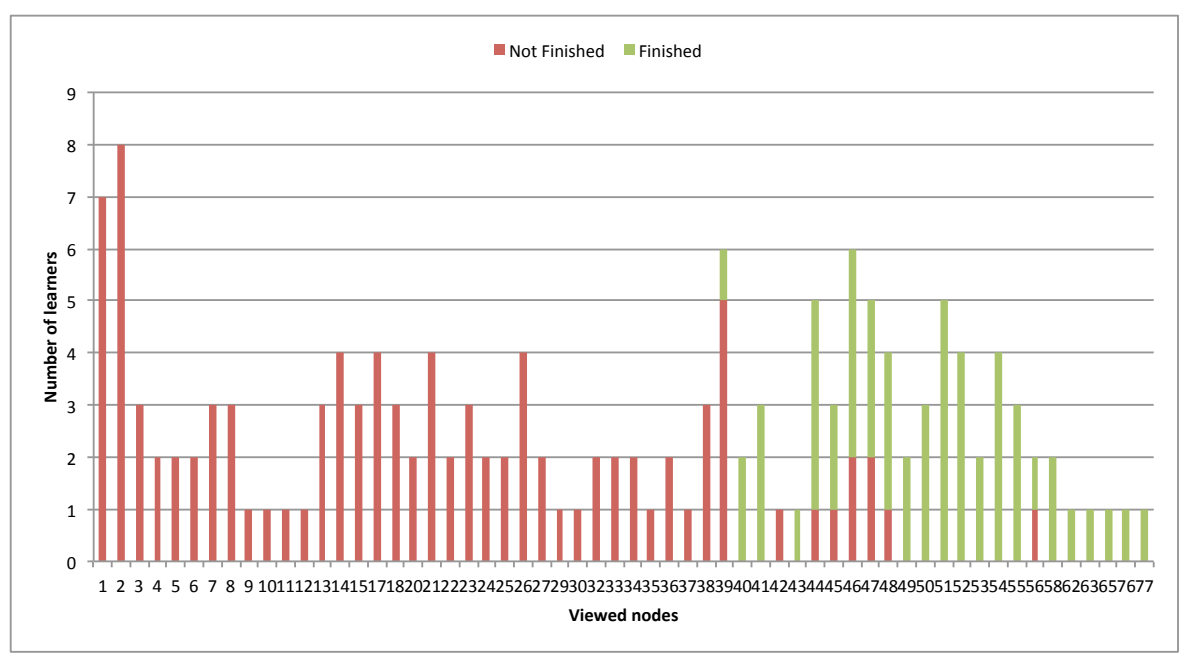

Fig. 3. number of learners per number of viewed nodes

\subsection{First Category: the Dropouts}

30 learners have viewed less than 8 steps (which represent $10 \%$ of the the game Les ECSPER). Among these: 5 have followed the 7 first nodes of the expected path and have attained the key node of the game (the working place of the main character); 3 have chosen the wrong answer at the first quiz. The exit node directly follows this step, when they have known they have made a mistake; 15 have only saw the first and or the second step without getting into the game. It will be interesting at the end of the MOOC if they make another try and what path they will take. If they will not do this, the design of the first and second steps would be revised.

\subsection{Second Category: the Good Paths}

44 learners have finished the game with one of the three good endings. It means that they have achieved the training objectives but they could have made some mistakes (only one learner have achieved the game with the highest score: "Excellent!").

Thus, among these learners paths, we have isolated an interesting fact. 25 learners of this category have made a major mistake at the step AB, a quiz step. We have extracted a sequence of nodes made by these 25 learners: [AB, AC, AU, AF] (Fig. 4). On Fig. 4, the expected path is the edge in light grey between the node $\mathrm{AB}$ and $\mathrm{AF}$ : $[\mathrm{AB}, \mathrm{AF}]$. Another sequence, $[\mathrm{AB}, \mathrm{AC}, \mathrm{AU}, \mathrm{AS}, \mathrm{AF}]$ includes the node AS which gives a second chance to the learner if he/she has one life left. We coloured the node $\mathrm{AB}$ and $\mathrm{AC}$ with the same colour (red) because this is the same screen for the learner but with a feedback (this is a second chance to find the true answer). We focus about this sequence in this analysis. Data visualization 


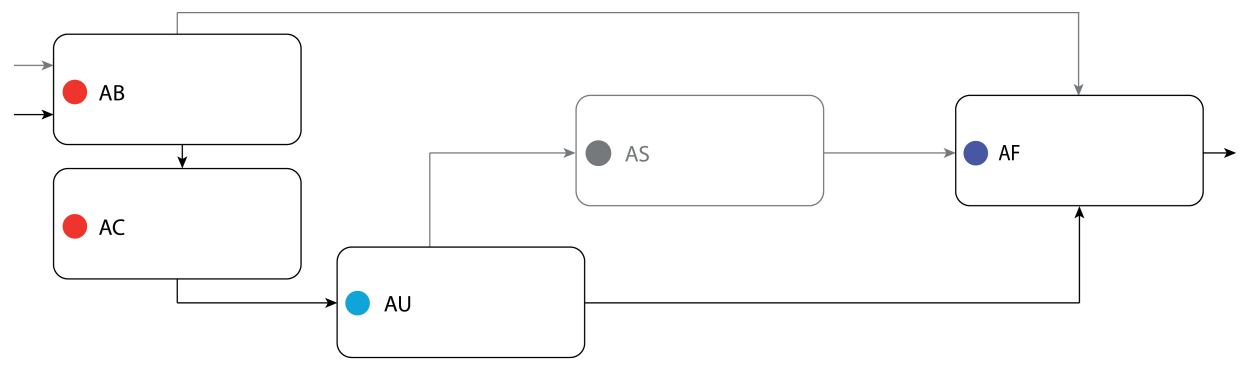

Fig. 4. A major mistake in the path of one learner (represented with Undertracks) and the part of the Mind Map associated

are built with Undertracks platform [9] (http://undertracks.imag.fr), a tool to capitalize and analyse data; it is maintained by LIG (Laboratoire Informatique de Grenoble).

\subsection{Third Category: the Bad Paths}

9 learners have finished the game with a "game over". In fact, they have made 4 mistakes that the teachers qualified as major mistakes (thus learners have lost one life for each of these). 5 of them have spent short time on the game: less

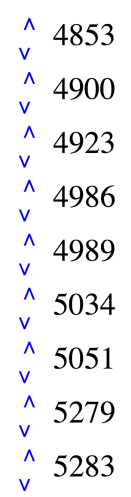

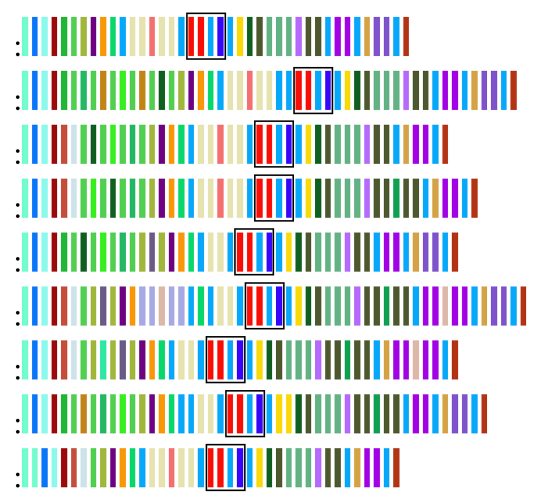

Fig. 5. Data visualization with Undertracks of the 9 learners who finished the game with a Game Over with sequence $[\mathrm{AB}, \mathrm{AC}, \mathrm{AU}, \mathrm{AF}]$

than 20 minutes. The authors have designed the game for at least one hour of 
play and work. We think that these learners just wanted to make a try and to see this new activity. We'll analyse their future try, if they'll make it, in a future work. On the Fig. 5, we note that the sequence [AB, AC, AU, AF] (we pointed out this with a black box) was always in the path.

\subsection{Fourth Category: the Abandonments}

About the other learners, we have analysed the paths of the 40 learners who have made more than $35 \%$ of the game. We have pointed out 2 situations of abandonment. A reason seems to be the type of the exit node: 29 have left the game on a quiz step noted "Quiz" and in blue in the Fig. 6. These nodes depict the important steps of the scenario. They are the key nodes of the predicted scenario defined by the teachers. Regarding the sequence [AB, AC, AU, AF], we

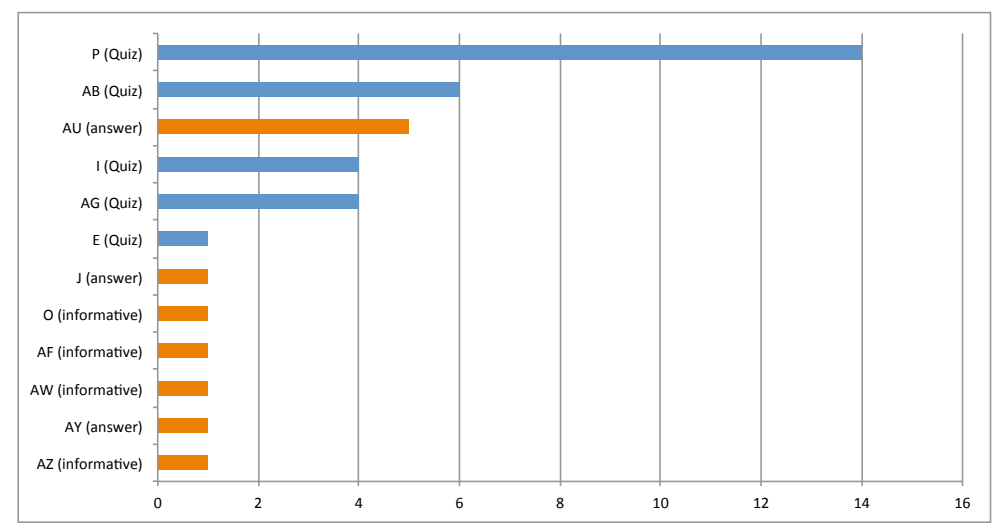

Fig. 6. Exit nodes for the learners who have made more than $35 \%$ of the game

have observed that 25 learners sequences of this category contained this sequence of nodes. The node AB is a quiz step, this is a typical example of key node. 6 learners of this category exited Les ECSPER at this step (Fig. 6). 13 learners exited the game at the step just following the node $\mathrm{AB}$ and all of them lost a point of life with the sequence $[\mathrm{AB}, \mathrm{AC}, \mathrm{AU}, \mathrm{AF}]$. Another reason is the case

\begin{tabular}{|c|c|c|c|c|}
\hline No life left & 1 life left & 2 lives left & 3 lives left & 4 life left \\
\hline $5 \%$ & $20 \%$ & $45 \%$ & $18 \%$ & $13 \%$ \\
\hline
\end{tabular}

Table 1. Lives left when the learners exit the game

where they were in a situation of failure. Thus, $70 \%$ of learners of this category (Table. 1) have lost 2 or more lives (the lives represent the level of confidence 
of the player). And of course, they know that if they lost 4 lives, the game is over. We don't know if they have left the game definitely or if they have made another try. The data exists and we'll analyse them in another paper.

Finally we could say that neither the time spent to play nor the score that calculates progression determine a situation of abandonment.

\subsection{To sum up}

If we focus on the sequence $[\mathrm{AB}, \mathrm{AC}, \mathrm{AU}, \mathrm{AF}]$, we observe that the learners lost often a point of life at the node $\mathrm{AB}$ (Table. 2) even between those who end the game successfully ( $57 \%$ have made a mistake at node $\mathrm{AB}$ ). This fact was noticed to the teachers, and this is an important element for a future reengineering of this learning game. Thus, for this sequence we have worked with one of the tesachers,

\begin{tabular}{|c|c|c|}
\hline Good Paths & Bad Paths & Abandonments \\
\hline $57 \%$ & $100 \%$ & $63 \%$ \\
\hline
\end{tabular}

Table 2. Learners that lose life at the node $\mathrm{AB}$

and he has proposed to add a step before the node $\mathrm{AB}$ with reminders. This new node will be integrated to the new version of the learning game.

\section{Perspectives}

We pointed out elements about the scenario that we could avoid. Three points need our attention:

- We have seen that the first and second steps will have to be revising to avoid an immediate exit of the game.

- The teachers could prepare the learners when the nodes include a quiz (or evaluation). To do that, they could add another fun elements and include them in the screenwriting. Also, they could rewrite the text of the quiz if it is needed.

- Finally, they would improve the feedback, especially when the learner make a mistake.

To improve all these points and to ease the reengineering, we would make a qualitative analyse of these data with the teachers. When they design this type of learning game, they could improve the game after the first real use. Thus, we must allow them to rework the screenwriting and so, we could make a reengineering of the learning game. Furthermore, we'll use a model and a tool created by Bertrand Marne, named respectively MoPPLiq and APPLiq [13][14]. MoPPLiq is a generic model able to describe the playful and educational aspects of the scenario of learning game and makes the scenario understandable and capable 
of being manipulated by teachers. This model comes with a tool called APPLiq enabling manipulation of the scenario to fit it into the educational background of teachers. This tool would allow us to ease the process of screenwriting, as the iterative step (as seen above). Indeed, in this step of design, we need a tool that enables the manipulation of the scenario. We define actually a formal model and predefined templates to ease the design phase, particularly the screenwriting. This model will guide teachers more closely in designing serious games.

The MOOC "Statistique pour l'ingénieur" is always open at the time of writing this paper and there will be another session in September 2016 which will increment the quantity of data. We have already a second (and sometimes a third) path recorded for learners who have not achieved the game. We prepare another paper including analyse of these new data and the qualitative analyse made with the teachers.

Acknowledgments This work was supported in part by the Institut Mines Telecom, UNISCIEL and Mines Douai. We would like to thank them for their support in the development of this project. The authors would like to thank Gaëlle Guigon, Carole Portillo and Rémy Pinot for their very helpful support to collect all this data; and of course the authors would like to thank the teachers who designed the learning game Les ECSPER, Michel Lecomte et Frédéric Delacroix based on an idea from Jean-Loup Cordonnier.

\section{References}

1. Abt, C.C.: Serious games. University Press of America (1987)

2. Alvarez, J., Djaouti, D.: An introduction to Serious game Definitions and concepts. In: Serious Games \& Simulation for Risks Management. p. 11 (2011)

3. Choquet, C., Iksal, S.: Modeling Tracks for the Model Driven Re-engineering of a tel System. Journal of Interactive Learning Research 18(2), 161 (2007)

4. Djaouti, D.: Serious Game Design: considérations théoriques et techniques sur la création de jeux vidéo à vocation utilitaire. Ph.D. thesis (2011)

5. Egenfeldt-Nielsen, S.: Practical barriers in using educational computer games. On the Horizon 12(1), 18-21 (2004)

6. Forment, M.A., Guerrero, M.J.C., González, M.A.C., Peñalvo, F.J.G., Severance, C.: Interoperability for LMS: The Missing Piece to Become the Common Place for Elearning Innovation. In: Lytras, M.D., Damiani, E., Carroll, J.M., Tennyson, R.D., Avison, D., Naeve, A., Dale, A., Lefrere, P., Tan, F., Sipior, J., Vossen, G. (eds.) Visioning and Engineering the Knowledge Society. A Web Science Perspective, pp. 286-295. No. 5736 in Lecture Notes in Computer Science, Springer Berlin Heidelberg (Sep 2009), dOI: 10.1007/978-3-642-04754-1_30

7. Freire, M., Blanco, A.d., Fernandez-Manjon, B.: Serious games as edX MOOC activities. In: 2014 IEEE Global Engineering Education Conference (EDUCON). pp. 867-871 (Apr 2014)

8. Lejeune, A., Pernin, J.P.: A Taxonomy for Scenario-Based Engineering. In: CELDA. pp. 249-256 (2004)

9. Mandran, N., Ortega, M., Luengo, V., Bouhineau, D.: DOP8: merging both data and analysis operators life cycles for technology enhanced learning. In: Proceedings 
of the Fifth International Conference on Learning Analytics And Knowledge. pp. 213-217. ACM (2015)

10. Marfisi-Schottman, I., Labat, J.M., Carron, T.: Building on the case teaching method to generate learning games relevant to numerous educational fields. In: Advanced Learning Technologies (ICALT), 2013 IEEE 13th International Conference on. pp. 156-160. IEEE (2013)

11. Mariais, C., Michau, F., Pernin, J.P., Mandran, N.: " Learning Role-Playing Games": méthodologie et formalisme de description pour l'assistance à la conception-Premiers résultats d'expérimentation. In: Environnements Informatiques pour l'Apprentissage Humain, Conférence EIAH'2011. pp. 95-107. Editions de l'UMONS (2011)

12. Marne, B.: Modèles et outils pour la conception de jeux sérieux: une approche meta-design. Ph.D. thesis (2014)

13. Marne, B., Carron, T., Labat, J.M., Marfisi-Schottman, I.: MoPPLiq: a model for pedagogical adaptation of serious game scenarios. In: Advanced Learning Technologies (ICALT), 2013 IEEE 13th International Conference On. pp. 291-293. IEEE (2013)

14. Marne, B., Labat, J.M.: Model and authoring tool to help teachers adapt serious games to their educational contexts. International Journal of Learning Technology 9(2), 161-180 (2014)

15. Marne, B., Wisdom, J., Huynh-Kim-Bang, B., Labat, J.M.: The six facets of serious game design: a methodology enhanced by our design pattern library. In: 21st Century Learning for 21st Century Skills. pp. 208-221 (2012)

16. Michael, D.R., Chen, S.L.: Serious games: Games that educate, train, and inform. Muska \& Lipman/Premier-Trade (2005) 